[Aus dem hygienischen Institut zu Berlin.]

\title{
Ueber das Verhalten der Schleimhäute und der äusseren Haut in Bezug auf ihre Durchlässigkeit für Bacterien. \\ Von
}

Dr. Otto Roth,

Assistenten am hggienischen Institut zu Zürich.

Manche Erfihrungen sprechen dafür, dass Mikroorginismen durch die unverletzte Schleimhant in den menschlichen Kürper eindringen kïnnen. So ist es besonders das Prodromalstadium exanthematischer Infectionskrankheiten, wie DLasern und Scharlach, die ja gewiihnlich durch Schlcimhauterkrankungen eingeleitet werden, welches uns die Möglichkeit eincr Infection auf diesem Wege anzunehmen berechtigt.

Dass auch die äussere Haut keine absolut sicher schützende Decke abgiebt gegen die Invision gewisser Mlikroorganismen beweisen hauptsïchlich die Versuche ron Garrél, welcher sich Culturen ron Staphylococcus pyogenes aureus in die Haut des Vorderarms einrieb und so eine starke Furunculosis an der Einreibungsstelle erzeugte, welche mit Lymphdrüsenschwellung und Fiebererscheinungen einherging.

Bei der grossen Wichtigkeit, welche der Entscheidung der Frage über die Durchlässigkeit der Haut und der Schleimhäute für Bacterien insbesondere fïr die Aetiologie mancher Infectionskrankheiten beizumessen ist, schien es mir von Interesse zu sein, dieselbe durch Thierrersuche und die mikrosliopische Untersuchung näher zu studiren.

Kurze Zeit bevor ich meine Versuche begann, hatte Rib b e $\mathrm{t}^{2}$ bei einer epidemischen Kaninchenkrankheit einen Bacillus gefunden, dem er den Namen „Bacillus der Kaninchendarmdiphtherie" beilegte. Er stellte mit

1 Garré, Zur tetiologie acut eitriger Entzündungen. Fortschritte der Medicin. 1885. Bd. III. Nr. 6.

* Deutsche medicinische Wochenschrift. 13. Jahrg. 1887. Nr. 8. 
Reinculturen desselben Versuche an Kaninchen an, indem er eine wässerige Emulsion dieses Mikrourganismus den Versuchsthieren in die Mundhöhle injicirte, was gewöhnlich den Tod zur Holge hatte. Gestützt auf die Thatsache, dass regelmässig die Halslymphdrüsen gesehwollen waren und dass sich die Bacillen durch die mikroskopische Untersuchung in den Taschen und dem Gewebe der Tonsillen in grosser Anzahl nachweisen liessen, zog Ribbert den Schluss, dass durch diese letzteren wenigstens ein Theil der Bacillen in die Lymphbahnen und das Blut gelangt sei. Durch Aufpinseln von Culturen auf die Zungenschleimhaut gelang es Ribbert nur dann eine Infection der Versuchsthiere von dieser Stelle aus herbeizuführen, wenn er vorher durch Aetzung mit Ammoniak eine Nekrose des Epithels erzeugt hatte, oder wenn er die Culturen mit einem derbeu Pinsel, der oberflächliche Epithelablüsungen bewirkte, einrieb. Ans diesen Versuchsresultaten zieht Ribbert den Schluss, dass die nicht verletzte Mundschleimhaut nur da für den ron ihm gefundenen Spaltpilz durchgïngig sei, wo sie schon in der Norm gelockert ist, nämlich an den Tonsillen. Es lag nun die Frage nahe, ob unverletzte Schleimhäute überhaupt nur an solchen gelockerten Stellen von Jiliroorganismen durchdrungen werden können. Ich wollte vorerst prüfen, ob die Mundschleimhaut nicht doch ausser an den Tonsillen noch an anderen Stellen dem Ribbert'schen Bacillus als Eingangspforte in den Thierkörper dienen könne, ohne dass vorher irgend eine Verletzung stattgehabt hätte. Herr Geheimrath $\mathrm{K} 0 \mathrm{ch}$, in dessen Institut ich diese Untersuchungen ausführte. hatte die Güte, mir eine von Professor Ribbert herstammende Cultur zur Verfügung zu stellen. Von dieser impfte ich nun kleine Mengen auf schrảg erstarrte Gelatine über. Meine Culturen hattell genau das Aussehen, wie es von Ribbert beschrieben worden; nur müchte ich hier noch beifügen, dass die Gelatine sich nach einiger Zeit um den Impfstrich herum zu trüben beginnt, stets aber eine sehr schmale helle Zone zwischen Trübung und Cultur übrig bleibt. Der Bacillus ist beweglich und, wie auch Ribbert betont, im Gewebe sehr schwer gut zu färben.

Ich strich nun Kaninchen eine Portion einer solchen Cultur mit einem ganz weichen Pinsel, ohne stark zu reiben, auf die Rachenschleimhaut auf. Das Ergebniss der drei auf diese Weise angestellten Versuche war folgendes:

I. Versuch. Eine Platinöse einer Cultur mit einem Pinsel auf die Rachenschleimhaut aufgetragen.

Bis zum neunten Tage keinerlei Verändermugen.

II. Versuch. Demselben Kaninchen eine grüssere Menge (drei Oesen) einer Cultur des Ribbert'schen Bacillus auf die Rachenschleimhaut aufgetragen. Auch diesmal keine Veränderungen. 
Da auch dieser Versuch ohne Resultat geblieben war, prüfte ich die Virulenz der verwendeten Cultur an demselben Thiere durch subcutane Impfung am linken $\mathrm{Ohr}$. Schon am dritten Tage nach der Impfung war die Impfstelle und ihre Umgebung stark geröthet. Am vierten Tage liessen die entzündlichen Erscheinungen etwas nach. Am fünften Tage starke Ectasie der Blutgefässe des Ohres centralwärts von der Impfstelle. Am achten Tage Fresslust des Thieres aufgehoben. Es sitzt zuisammengekauert in seinem Käfig. Am neunten Tage erfolgte der Tod. Der Sectionsbefund war folgender: Um die Impfstelle herum Rïthung der Haut.

Submaxilläre Lymphdrüsen und Mandibulardrüsen links stark, Suhmaxillardrüsen rechts nur ganz wenig geschwollen.

Rachenschleimhaut normal. Leber: Einzelne kleine weisse, nicht pruminente Knötchen. Milz ganz von kleinen Knötchen durchsetzt. Darm stellenweise etwas geröthet, kleine Ecchymosen, kein Belag.

Dieser Sectionsbefund stimmte vollständig mit den ron Ribhert beschriebenen Veränderungen überein, ebenso das Resultat der mikruskopischen Untersuchung von Leber und Milz. Die Bicillen liessen sich in sehr grosser Anzahl in den schon makroskopisch sichtbiren Knïtchen, oft auch in den Capillaren nachweisen.

Esmarch'sche Röhrchen von Milz- und Leberpartikelehen wiesen cine grosse Henge Colonieen dieses Spaltpilzes auf.

Der III. Tersuch, der auf dieselbe Weise an einem Kíminchen angestellt wurde, blieb ebenfalls resultatlos.

Das Ergebniss dieser Untersuchungen scheint die Ansicht Ribbert's: dass die Inndschleimhaut eine schützende Decke gegen die Einwanderung: dieses Mikroorganismus bilde, zu unterstützen.

In einer weiteren Versuchsreihe machte ich es mir zur Aufgabe, die Nasenschleimhaut auf ihre Durchlässigkeit für Bacterien zu prüfen.

Ich rerwendete hierzu wiederum den Ribbert'schen Bacillus, wozu ich umsomehr Grund hatte, als inzwischen Dr. Braunschweig, der zur selbigen Zeit im hygienischen Institut zu Berlin Studien über diesen Spaltpilz machte, fast immer eine Infection seiner Versuchsthiere beobachtete, wenn er ihnen eine kleine Portion einer Cultur desselben in den Conjunctivalsack brachte. Ich strich num Kaninchen, Mäusen und Meerschweinchen ganz kleine Hengen solcher Mikroorganismen ohue zu reiben in das eine Nasenloch und zwar rermittelst eines ganz weichen Pinsels oder einer Oese aus dickem Platiudraht, so dass eine Verletzung mit sicherheit ausgeschlossen werden konnte. Auf diese Weise stellte ich sechs Versuche an. 
I. Versuch. Einem Kaninchen eine Oese einer Ribbertcultur vermittelst Pinsel in das linke Nasenloch eingestrichen.

Am vierten Tage weissliches Secret aus dem linken Nasenloch und dem linken Auge. Dieser Ausfluss steigert sich bis zum siebenten Tinge, daun nimmt er ab. Sonst keine Veränderungen. Allgemeinbefinden normal.

Nach vier Wochen subcutane Impfung am linken $0 \mathrm{hr}$, welche am dritten Tage starke Röthung der Impfstelle und Umgebung zur F'olge hatte. Am fünften Tage Bildung eines harten Knotens an dieser Stelle, welcher abscedirt und sich am siebenten Tage spontan erüfnet. Der Abscessinhalt enthielt ziemlich reichliche Bacillen, am zweiten Tage war die Wunde geschlossen. Das Thier war nicht krank.

Um zu prüfen, ob dasselbe vielleicht durch Aufnahme der Spaltpilze durch die Nasenschleimhaut immun geworden sei, impfte ich ein anderes Kaninchen an einem Ohre und hatte wiederum genau dieselben Erscheinungen zu constatiren. Auch dieses Thier erkrankte nicht.

Es ist daher die unschädliche Wirkung der subentanen Impfung bei dem Kaninchen, welchem vorher Ribbert'sche Spaltpilze auf die Nasenschleimbaut gebracht worden waren, kaum in Zusammenbang zu bringen mit einer früheren Infection von dieser Stelle aus. Die ungeschwächte Virulenz der verwendeten Culturen war auch hier durch Controlversuch festgestellt worden.

II. Versuch. Einer weissen Maus eine Platinöse einer Cultur des Ribbert'schen Bacillus mit einem Pinsel in das linke Nasenloch eingegestrichen. Resultat: Am zweiten Tage starker weisslich trüber Ausfluss aus dem linken Nasenloch. Am dritten Tage Verklebtsein des linken Auges, starke Conjunctivitis. Am sechsten Tage: Thier todt.

Sectionsbefund: Leber: keine Veränderung. Milz: viele kleine weisse Knötchen. Darm: Im Dünndarme. an einer Stelle diphtheritischer Belag; Ferdickung der Darmwand im mittleren Drittel derselben. An vielen Stellen Röthung und Ecchymosen. Mesenterialdrüsen: Submaxillardrüsen links sehr stark geschwollen, Submaxillardrüssen rechts normal.

In Blut, Leber und Milz viele Bacillen.

Esmarch'sche Röhrchen von Leber und Ifilz zahlreiche Colonieen.

III. Versuch. Einer weissen Maus eine Oese einer Ribbertcultur in das linke Nasenloch eingestrichen. (Aus Versehen gelangte eine ganz kleine Menge der Cultur anch in das rechte Nisenloch.)

Resultat: Zweiter Tag: Ausfluss aus beiden Nasenöffnungen. Am dritten Tage Verklebtsein und Conjunctiritis beider Augen. 'Tod am 11. Tage. 
Sectionsbefund: Submaxillare Lymphdrüsen links und rechts stark geschwollen. Lungen: Kleine weisse Knötchen. Leber und Milz: Vielu kleine Herde. In der Leber ein grosser Knoten. Nieren ebenfalls einige Knötchen. Dünndarm: Kleine harte weisse Knötchen in der stellenweise verdickten Darmwand. Kein diphtheritischer Belag. Röthung. Einige geschwollene Mesenterialdrüsen.

Nasenschleimhaut etwas geröthet, sonst normal. Mundschleimhaut und Rachenschleimhaut normal. Mikroskopischer Befund: Milz und Leber viele Bacillen. Esmarch'sche Röhrchen: viele Colonieen.

IV. Versuch. Finem Meerschweinchen eine sehr kleine Portion einer Ribbertcultur in das linke Nasenloch eingestrichen. Am dritten Tage starker Ausfluss aus der linken Nasenöffnung. Conjunctiva des linken Auges etwas geröthet und zuletzt reichlich secernirend. Der Tod erfolgte am 13. Tage.

Sectionsbefund: Submaxilläre Lymphdrüsen beiderseits geschwollen, diejenigen der linken Seite mehr als die der rechten.

Nasenschleimhaut links gerïthet. Darmschleimhaut an einigen Stellen etwas geröthet, sonst normal. Mesenterialdrüsen stark geschwollen.

Leber: Einige stecknadelkopfgrosse Knitchen. Milz: desgl., etwas vergrössert. Nieren normil. Esmarch'sche Röhrchen ron Leber und Milz zahlreiche Colonieen.

V. Versuch. Einem Meerschweinchen eine Oese einer Ribbertcultur in das linke Nasenloch eingestrichen. Am dritten 'Tage starker weisslich trüber, später eitriger Ausfluss aus der linken, vom fünften Tage an auch aus der rechten Nasenöffnung. Linkes Auge starke Conjunctivitis. Tod erfolgte am 11. Tage.

Sectionsbefund: Submaxilläre und Halslymphdrüsen besonders links stark geschwollen. Nasenschleimhaut rechts catarrhalisch afficirt, weniger links. Am linken Auge starke Conjunctivitis. Rachenschleimhaut normal. Leber einzelne kleine knotenförmige Herde. Milz einzelne stecknadelkupfgrosse K̄nötchen. Darm: schwache Röthung, sonst normal. In Milz und Leber viele Bacillen.

VI. Versuch. Einem Meerschweinchen eine Oese einer Ribbertcultur in das linke Nasenloch gestrichen. Am vierten Tage starke Secretion der Schleimhaut der linken Nasenhälfte. Am sechsten Tage starke Röthung des linken Naseneinganges. Am 12. Tage Conjunctivitis des linken Auges mit reichlichem Secret. Fresslust beinahe aufgehoben.

Im 25. Tage erkrankt auch das rechte tuge. Das Thier frisst wieder normial. $\pm \mathrm{m}$ 30. Lage Secretion der Nasenschleimhaut bedeutend rer- 
mindert. Am 36. Tage linkes Auge wieder normal, rechtes sondert noch weisslich trübes Secret alb, sonst normal. Am 59. 'lage wird das Thier, das sich vollständig erholt hat, getödtet. Die Suction ergiebt fulgendes: Leber zwei weissliche Knötchen, Jilz viele kleinere Knötchen. Submaxilläre Lymphdrüsen wenig geschwollen. Nasen- und Rachenschleimhaut normal. Rollröhrchen aus Leber und Milz: ziemlich kleine Anzahl von Colonieen des Ribbert'schen Bacillus.

VII. Versuch. Einem Meerschweinchen eine minimale Quantität einer Ribbert'schen Colonie in das linke Nasenloch eingestrichen. Am 4. Tage Schleimhaut des linken Naseneinganges etwas goröthet, kein reichliches Secret. Am 11. Tage schwache Conjunctivitis links. Am 16. T'age geht die Entzündung des linken Auges zurück. Am 21. Tage nichts Abnurmes mehr wahrzunehmen. Fresslust war nie ganz aufgehoben. Am 29. Tage brachte ich eine ganze Oese einer Ribbert'schen Cultur anf die rechte Nasenschleimhant. Am 36. Tage schwache Secretion der Nasenschleimhaut dieser Seite. Das Allgemeinbefinden des Thieres schien fortwährend normal zu sein. Auch die zwei Monate später angestellte Suction ergab nichts Abnormes.

Auf der Nasenschleimhaut konnte ich in keinem der sieben zur Section gelangten Fälle makroskopisch sichtbare Verletzungen der Schleimhaut wabrnehmen.

Es hat also in diesen Versuchen bei sämmtlichen Thieren, nämlich einem Kaninchen, zwei Mäusen und rier Meerschweinchen eine locale Erkrankung nachgewiesen werden kïnnen. Bei zwei Meerschweinchen and den beiden Mäusen erfolgte der Tod. Bei dem Meerschweinchen in Versuch Nr. 6 wurde die Infection durch die Section des am 59. Tage getïdteten Thieres festgestellt. $O b$ bei dem Kaninchen in Versuch Nr. 1 Bacillen in den Thierkörper gelangt sind, ist nicht zu entscheiden; bei dem Meerschweinchen in Versuch 7 ist dies unwahrscheinlich.

Es kann nun zwar nicht ausgeschlossen werden, dass mit dem Nasensecret Keime in die Rachenhühle und so in den Magendarmeanal gelangt seien; im Gegentheil sprechen hierfür die in dem Sectionsbefund des Verstuches 2 und 3 aufgeführten Verïnderungen des Darmeanals. Jedenfalls aber lässt die constante Erkrankung der Nasenschleimhaut und die in sechs Versuchen nachgewiesene Schwellung der regionären Lymphdrüsen mit Sicherheit darauf schliessen, dass auch auf diesem Wege eine Infection der Thiere stattgefunden bat. 
Nachdem es mir nun gelungen war, den Ribbert'schen Bacillus durch die unverletzte Nasenschleimhaut in den Thierkörper einzuführen, prüfte ich in meinen weiteren Versuchen die ïussere Haut auf ihre Durchlässigkeit für einige Arten von Mikroorganismen. Ich verwendete dabei den Bacillus von Ribbert und diejenigen der Mäusesepticämie und des Milzbrandes und rieb diese in vorher sorgfältig auf die Abwesenheit von Verletzungen geprüfte Hautstellen ein, oder aber strich sie nur auf dieselben auf, und zwar wurden diese Stellen so gewählt, dass sich die Thiere nicht durch Ablecken derselben inficiren konnten. Letztere wurden stets cinzeln in einen Kïitig gesperrt, so dass auch die Infection eines Thieres durch ein anderes ausgeschlossen war.

Da manche feste fein vertheilte Kürper in dic Hatut besser cindringen, wenn sie mit fettigen Substanzon gemischt werden, su versetzte ich eine kleine Menge der Cultur mit Lamolin, Adeps suillus veder Olivenül. In weiteren Versuchen wurlen eine his zwei Platinösen einer reliatinecultur unvermischt eingerieben. Dis Gimpeihen geschah mittehts Guttiperchilpapier. Die Hände schütate ich durch Kintschaklamolschuhe.

\section{A. Hinreibungsversuche nit den Ribbert'schen Bacillus.}

I. Einreibung mit Ianolin vermischter culturen.

I. Versuch. Einem Meerschweinchen eine Oese eincr Cultur in dit. Aussenflüche des rechten Ohres eingerieben. Bis zum 5. Tage nichts Alnormes zu bemerken; dam begann sich die Eimreibungsstelle zu röthen und heiss zu werden. Am 11. Tage starke Entzündung auch der Umgebung. Lymphdrüsengeschwulst von der Grüsse einer Erbse hinter dem rechten Ohre. Am 15. Tage neben dieser Geschwulst eine zweite kleinere. Das Thier frisst nicht mehr. Am 25. Tilge eröffnct sich die erste Drüsengeschwalst spontan. Die zweite hat die Grüsse einer Wallnuss erreicht und bildet sich vom 32. Tage an zurück. 1)as Thier frisst. normal. Es wird am 41. Tage, nachdem es sich vollstïndig erholt zu haben schien, getüdtet.

Sectionsbefund: Leber: Am Rande ein grosser Inoten. Milz: Viele kleine weissliche Knn̈tchen. Im Coecum einige runde; plaqueartige Verlickungen. Im Darm nirgends diphtheritische Erscheinungen. Eininge geschwollenè Mesenteriuldrüsen.

Mikruskopischer Befund: Milz und Leher viele, wher sehr schlecht 
oder gar nicht sich färbende Bacillen. Esmarch'sche Röhrchen aus diesen Organen viele Colonieen.

II. Versuch. Zwei Oesen Ribbert'scher Bacillen mit Lanolin links neben dem Rückgrate auf der Höhe der letzten Rippe in die geschorene aber nicht rasirte Haut eingerieben.

Am 3. Tage Röthung der Einreibungsstelle. Am 6. Tage starke Entzündung und Geschwulst der Umgebung. Am 12. Tag beginnt sich die Entzündung zurückzubilden. Am 14. Tage an der Einreibungsstelle ein kleiner harter Kinoten, der nachher abscedirt. Fresslust bedeutend herabgesetzt. Am 18. Tage erüfuet sich der Knoten spontan. Es entleert sich der gelblich weisse dickflüssige Inhalt. Durch Esmarch'sche Rollrührchen konnte in diesem eine geringe Zahl von Ribbert'schen Bacillen nachgewiesen werden. Dis Thier erholte sich vollstïndig. Is wurde nicht secirt, sondern später zu anderweitigen Versuchen rerwendet.

III. Versuch. Vier Oesen Ribbert'scher Bacillen mit Linolin an derselben Stelle des Rückens eingerieben wie im letzten Versuch.

An 4. Tage Röthung der Finreibungsstelle, am 7. Tage starke Entzündung. Fresslust bedentend vermindert. Tom 17. Tage an Rückbildung der Entzündnng in der Umgehung der Einreibungsstelle; an dieser lileine Hautalbseesse, welche sich spontan eröffnen. Durch Rollröhrchen wurdr in diesem Abscessinhalt eine mittlere Qumtitït Ribbert'suher Bacillen nachgewiesen. Das Allgemeinbefinden des Thieres blieb normal. Auch hier find keine Section statt.

IV. Versuch. Ein Mcerschweinchen an derselben Stelle mit Ribbert'schen Bitcillen und Limulin eingerieben. Diss Thicr zeigte dieselben Teränderungen an der Einreibungsstelle; es starb um 23. Tage. Die Section ergab grosse Knnoten in Leber und Milz, kleine Knütchen in der Iunge.

Deckgliaspräparate liessen nur undeutlich die fast gar nicht gefärbten Bacillen erkennen. In Rollrührchen mit Partikelchen ron Leber und Milz wuchsen viele Cúlonieen.

\section{Einreibung von Culturen mit Adeps suillus vermischt.}

Versuch. Einem Meerschweinchen eine Oese Ribbert'scher Bacillen mit Adeps auf der linken Seite des Halses eingerieben.

Die Hautstelle wurde vor der Finreibung geschoren, aber nicht rasirt. um Verletzungen zu vermeiden. An der Einreibungsstelle und in deren Lmgebung dieselben Verïnderungen wie bei den früheren Versuchen. Das Thier erholt sich vollstindig und wird am 32. Tage getültet. Die 
Section ergiebt ein geschwollenes Lymphdrüsenpaquet in der linken Achselhöhle, kleine Knoten in der Milz, grosse Knoten in der Leber, welche zum Theil erweicht sind. Rollrührchen ron Leber und Milz ergeben reichliche Colonieen.

\section{Einreibung ron Culturen mit Olivenöl vermischt.}

Versuch. Einem Meerschweinchen eine Oese Ribbert'scher Bacillen mit Olivenöl vermischt hinter das linke Ohr eingerieben.

Auch hier dieselben Veränderungen der Haut. Das Thier erholte sich rollständig. Es wurde am 32. Tage getiddtet.

Die Section ergab: Grosse prominente Knoten in Ireber und Milz. Die Knoten in der Leber zum Theil erweicht, mit breiartigem Inhalt. Fin Paquet selur stark geschwollener Lymphdrüsen in der linken Halsgegend. Die angelegten Rollrührchenculturen ergaben wiederum grossen Bacillenreichthum von Leber. und Milz. Der Inhalt eines erweichten Kunutens erwies sich als nicht bacillenhaltig. - In diesem letateren Versuche wählte ich die unbehainte Stelle hinter dem Ohre, um dem Einwurf zu begegnen, es kïnnte die Infection durch eine beim Scheeren rerletate Hilutstelle staltgehabt haben.

\section{B. Einreibungsversuche mit Mäusesepticämie.}

I. Versuch. Einer weissen Maus eine Oese einer Cultur von Mäusesepticimie mit Lanolin vermischt in die Aussenfliiche des rechten Ohres eingerieben. - Dieser Versuch blieb ohne Resultat, was wohl seinen Grund darin gehabt haben mag, dass das Ohr wegen seiner Kleinheit bei der Einreibung nicht genügend fixirt werden konnte und deshalb ein ausgiebiges Reiben unmüglich war.

II. Versuch. Einer weissen Maus eine lileine Portion einer Cultur von Mäusesepticämie mit Lanolin vermischt in die vorher geschorene Haut des Halses links neben dem Rückgrat eingerieben.

Die Augen waren am 3. Tage verklebt; an der Haut war nicht:: wahrzunehmen. Der Tod erfolgte am 4. Tuge.

Sectionsbefund: Die Haut zeigt an der Finreibungsstelle in der Durchsicht eine leichte Röthung und etwas Oedem. Milz geschwollen, Iunkelroth.

Die mikroskopische Untersuchung ergab eine grosse Anzahl ron Bilcillen besonders in der Milz. 
Die Einreibungsstelle zeigte auch nach der Einreibung keine Spur ron Verletzung.

\section{Einreibungsversuche mit Milzbrand.}

Als Fimreibungsstelle wurle auch hier aus dem vorhin angesleuteten Grunde die unbelharte Hant hinter dem Ohre gewiihlt.

I. Einreibung von Culturen mit Lanolin vermischt.

I. Versuch. Hin Meerschweinchen. Einreiloungsstelle: Hiut hinter rlem linken Ohr. An der Oberfläche der Halut war nichts Abnormes nachzuweisen. Das 'Thier starl) am 4. Tage. Die Section ergah: Oerdem des Unterhuntzellgewebes an der Einreibungsstelle und deren Umgelımg. Milz und Teber dunkel. blauroth, vergrëssert. In rliesen Orgatne'n sowohl als im Blute riele Milzbraudbacill’n.

IT. Versuch. Fin Mreerschweinchen eingerieben wie bei Tersuch I. Kén Resultat. Das 'Thier erkinnlite nicht.

IIr. Versuch. Finem Meerschweinchen Milzhrand mit Tanolin hinter las rechte Ohr eingerieben. Diese Hantstelle rom 3. Tige an deutlich ind matïs. 'Thier am 4. Tage tult.

Sectiousbefund: Hant an der Finrcilnungsstelle bei durehscheinendem Lichte leicht geröhet, stimk ïlemitris. Leber und Milz vergrissert. hlauroth. In diesen Organen und im Blnte eine grosse Anzahl Bacillen.

\section{Hinreibung einer Cultur mit Adeps vermischt.}

Versuch. Einem Mperschweiuchen Milzbrand mit Adeps hinter disis rechte Ohr eingerieben. Während des Tebens keine Verïnderungen aut der Hautoberfläche. Das Thier starb am 3. Tage. Sectionsergebuiss wie im vorigen Versuche.

\section{Einreibung einer mit Olivenöl vermisehten Cultur.}

Versuch. Ein Meerschweinchen. Am dritten Tage etwas Rüthung der Einreibungsstelle. Das Thier starb am vierten Tiage.

Sectionsbefund: Schwache Rüthung der Haut an der Einreibungsstelle: Unterhautzellgewebe hier etwas üdematüs. Milz und Leber blauroth, etwas rergrïssert. grosser Bacillenreichthum in diesen Organen und im Blut. 
IV. Einreibung unvermischter Milzbrandeulturen. (Ohue Fett.)

I. Versuch. Einem Meerschweinchen wenig Milzbrand hinter dem linken Ohre eingerieben. Die bezeichnete Hautstelle zeigte nach der Einreibung trotz Untersuchung mit der Loupe keinerlei Verletzung. Tod am siebenten Tage. Die Section ergiebt hochgradige Erkrankung und grossen Bacilleureichthum von Leber und Milz. Oedem der Einreibungsstelle.

II. Versuch. Finreibung wie beim ersten. Tod am siebenten Tage. Sectionsbefund derselbe wie in Versuch I.

III. Versuch. Meerschweinchen. Einreibung wie bei I und II. Tod des 'Thieres am siebenten Tage. Sectionsbefund wie in den vorhergehenden Versuchen.

IV. Versuch. Ein Meerschweinchen. Einreibung wie in Versuch I, II und III. Tod erfolgte am siebenten Tage. Sectionsbefund: Hochgradiger Milzbrand.

V. Versuch. Einreibung wie in den vorhergehenden. Das Thier erkrinkt nicht. - Ein Meerschweinchen, dem zur selbigen Zeit etwas von der Milzbrandcultur, welche in Versuch I verwendet worden, unter die Haut des Ohres gebracht wurde, war am dritten Tage todt, während die Thiere der obigen Versuche ausser demjenigen in Nr. V, welches gar nicht erkrankte, alle am siebenten Tage erst starben. Es geht daraus hervor, dass die Resorption nicht mit Fett vermischter Milzbrandeulturen durch die Haut eine relativ langsame ist.

In einer weiteren Versuchsreihe wollte ich erfahren, $a b$ nicht Mikrourganismen, ohne dass sie in die Haut eingerieben werden, in dieselbe eindringen und so in den Thierkörper gelangen können. Zu dem Zwecke strich ich den Thieren auf die schon früher bezeichnete Stelle hinter dem Ohre eine ziemlich grosse Menge einer Gelatinecultur. Solche Versuche wurden angestellt mit dem Ribbert'schen Bacillus an drei Meerschweinchen und mit Milzbrand an vier Meerschweinchen. Die Thiere zeigten ille keine Veränderungen und waren im Verlaufe ron zehn Wochen alle vollständig gesund geblieben.

Nachdem ich so festgestellt hatte, dass eine Infection durch die Haut. nicht stattfindet, ohne dass die Mikroorganismen in dieselbe eingerieben werden, wollte ich noch prüfen, ob ein ziemlich anhaltendes Reiben, wie es in den vorhergehenden Versuchen immer angewendet wurde, nöthig sei, oder aber ob ein mehrmaliges Hin- und Herreiben mit Anwendung eines ganz leichten Druckes schon genüge. 
Ich verwendete zu diesen Versuchen den Ribbert'schen Bacillus und rich, Culturen davon drei Meerschweinchen ganz sacht in jene unbeharite stelle hinter dem Ohre ein. Zwei Anderen aber rieb ich Culturen desselben Bacillus etwas energischer ein. In allen fünf Fällen wurden die Culturen nicht mit Fett vermischt. Die drei ersten Meerschweinchen blieben vollständig gesund bis zum 52. Tage. Die Section der getïlteten 'Thiere ergab keinerlei Veränderungen. Das eine der zwei ïbrigen Mcerschweinchen erkraukte ebenfalls nicht und zeigte auch bei der Suction keine Veränderungen. Bei der Section des anderen aber, welches ebenfalls bis zum 52. Tage ansser einer leichten Hautröthung an der Einreibungsstelle keine Veränderungen aufwies und vollständig gesund zu sein schien, fand ich einen ziemlich grossen harten Knoten in der Leber, in der Milz wonige kleinere Kinütehen und zwei kleine narbige Einzichungen. In den Knoten der Leber sowohl als in der Milz fand ich eiue grosse Miasse Bacillen.

In den ersten scchs Einreibungsversuchen mit dem Ribbert'schen Bicillus waren also vier Thicre nachgewiesenermassen erkrankt, das cine stallb am 23. Tage, zwei wurden am 32. Tage und das letzte am 41. Tage getijdtut. Alle vier Neerschweinchen zeigten bei der Section hochgradige Veräudurungen, die vollstïndig mit den von Ribbert beschriebenen überuinstimmten. Bacillen konnten selbst an dem erst am 41. Tage nach der Einreibung getödteten Thiere noch nachgewiesen werden und zwar theils durch Esmarch'sche Röhrchen, theils durch Deckglaspräpariate, theils an Sehuitten. Diese letzteren liessen sich noch am besten fïrben, wenn ich sie zuerst $1 /$ Stunde in 1 procent. Oxalsäure, dann zweimal 24 Stunden in wässeriger Methylenblaulösung liegen liess und hierauf mit 1 proc. Essigsäure und Alkohol behandelte. Die Bacillen waren dann in den Linötchen der Milz und der Leber meist gut zu sehen, ebenso fand ich sie oft in den Capillaren. Leider erhielt ich aber auch mit dieser Färbemethode nicht regelmässig gute Bilder. - In den Versuchen mit Müusesepticïmie starb ron den zwei Mäusen nur eine. Eine Verletzung der Haut konnte auch hier trotz der sorgfältigsten Untersuchung vor und nach der Einreibung nicht wahrgenommen werden.

Mit Milzbrand und Lanolin wurden eingerieben: drei Thiere; davon stiluben zwei am vierten Tage, eines erkrankte nicht. Mit Milzbrand und Adeps: ein Thier, welches am dritten Tage starb. Mit Milzbrind und Olivenöl ein Thier, dessen Tod am vierten Tage erfolgte.

Mit Milzbrand allein fünf Thiere; davon starben vier am siebenten Tage, cines erkrankte nicht. In den sieben Fällen, in denen Milzbrand 
sler Ribhert'sche Bacterien nur auf die Haut anfgestrichen wurlen, erfulgte heine Lrkrankung, ebenso wenig wie bei den drei T'hieren, denon der Ribbert'sche Bacillus nur ganz schwach in die Haut eingerieben wurde.

Aus diesen Versuchsresultaten geht herror:

1. Die Vermischung der einzureibenden Culturen mit Fetten seheint nich den Versuchen mit Milzbrand zu schliessen die Resorption zu begünstigen, wohl, weil durch die Geschmeidigkeit des Fettes die Vertheilung und Verreibung der Bacterien erleichtert wird. Welches Fett man anwendet, ist gleichgültig; auch Lanolin, von welchem man wegen seiner Verwandtschaft mit dem der Hilut eigenthümlichen" Cholestearinfett vielleicht ron rorneherein hätte annehmen mögen, dass es anderen F'etten überlegen sei, erwies sich in dieser Hinsicht denselben vïllig gleich.

2. Dass ein ziemlich ausgiebiges Reiben nothwendig ist, um dise Mikroorganismen durch die Haut eindringen zu lassen. Aus diesem letzteren Umstande mijehte num vielleicht doch geschlossen werden, dass allfällige durch dis Reiben entstiundene Verletzungen übersehen worden scien.

Um diesem letzteren Einwande zu begegnen, machte ich Schnitte lurch die Hant an den stellen, wo die Mrilzbrandbacillen eingeriehen worden waren. Die Epidermis war stets intact. Fs fanden sich eine grusse Masse Milzbrandstäbchen in den Capillaren unter dem Rete Malphigi; viel seltencr find ich solche in Querschnitten ron Hilarbälgen, nie wher in der Epithelsehicht. Um die Frage zu entscheiden, ob die Bacillen vielleicht schon alle durch dic Epidermis durchgegangen, rieb ich einem Meerschweinchen Milzbrand hinter dem Ohre ein. impfte es aber zugleich in einer anderen Stelle subeutin. Der Tod erfolgte am dritten I'ige. Ich untersuchte nun wiedcrum die Haut der Einreibungsstelle und find denn auch Bacillen in der Epithelschicht, welche nirgends Zeichen von Verletzungen zeigte. In Hautstückchen, welche ich weit von den Infectionsstellen entfernt ausgeschnitten hatte, fand ich die Stäbchen meist nur in den Gefüssen des Unterhautzellgewebes, sehr viel seltener in den Capillaren unter dem Rete Malphigi und nie in der Epidermis. Somit ist festgestellt, dass Mikroorganismen durch die unverletzte Haut hindurch gehen können. Jedenfalls aber setzt diese letztcre der Einwanderung einen bedeutenden Widerstand entgegen. Ob dieser nuu durch das mit dem Lianolin mahe rerwandte Hiutfett bedingt wird, wie Gottstein aus seinen Versuchen (Ueber das Verhalten der Miikroorganismen gegen Lanolin. Berliner med.IFochenschrift. Nr.48. Jahrg. XIIV. $\$ .907$ ) folgert, ist durch meine Versuchsresultate nicht zu entscheiden. Es könnte für die Gottstein'sche Ansicht vielleicht der Lmstand sprechen. dass es mir nie gelang Bacillen in den Talgdrüsen zu finden. 
164 Otto Roth: Über das VehHaliten ber SchleinhäUte U. s. W.

Um den Weg, welchen die Mikroorganismen bei ihrer Einwanderung durch die Haut nehmen, genau festzustellen, würde es wohl nöthig sein, Thiere zu verschiedenen Zeitpunkten nach der Einreibung zu tödten und dann die betreffende Hautstelle $\mathrm{zu}$ untersuchen. Ich habe mich dieser sehr zeitraubenden Arbeit nicht unterzogen, da es mir hauptsïchlich daran lag, zu wissen, ob Bacterien durch die unversehrte Haut durchgehen köunen, was ich wohl zur Genüge festgestellt habe.

Hier sei es mir nur noch gestattet, Hrn. Geheimrath $\mathrm{Koch}$ moinen wärmsten Dank auszusprechen für die freundliche Unterstützung, die er mir während dieser Untersuchungen zu Theil werden liess. 